\title{
Using ATP- bioluminescence for Kitchen Hygiene Control of Alexandria University Dormitories
}

\author{
Soheir Fouad Nour ${ }^{1}$, Isis Nawar ${ }^{2}$, Mostafa Abo El Enen ${ }^{3}$ and \\ Abd Elazeez Ashry ${ }^{4}$
}

\begin{abstract}
:
This research aimed to investigate kitchen hygiene control of Alexandria University dormitories suing ATP- Bioluminescence and a questionnaire collected from a random sample of the employees who are working in the kitchen. The results are statistically tested using percents, Chi square and correlation coefficient. Findings cleared the need for more interest with offering training programs in food safety and hygiene to all the levels of workers in the dormitories to upgrade the levels of awareness and practices through food handling in the kitchen and food service.

Key words: Kitchen hygiene control, university dormitory, HACCP, ATP- bioluminescence.

\section{Introduction:}

Group feeding has greatly been developed within the last decades especially for large groups like universities' dorms, hospitals, schools, and armed forces ... etc. This concept differs from individual feeding as it requires preparing large amounts of food that, in turn, requires special equipment, adequate facilities, qualified personnel, and trained efficient workers for preparing healthy and safe meals ${ }^{(1)}$.

Food quality is not only limited to the sensory side and chemical composition, but also it includes safe foods that are free of harmful substances as a result of exposing it to contamination or spoilage. There are three major causes of food-borne disease in foodservice operations these are poor personal hygiene, cross contamination, and time-temperature abuse ${ }^{(2)}$. In Egypt there is no accurate statistic

1-Soheir Fouad Nour, Professor of Food and Nutrition, Home Economics Department, Faculty of Agriculture, El-Shatby, University of Alexandria, Alexandria, Egypt soheir.nour@hotmail.com

2- Isis Nawar, Professor of Food and Nutrition, Home Economics Department, Faculty of Agriculture, El-Shatby, University of Alexandria, Alexandria, Egypt.

3- Mostafa Abo El Enen, Assistant Professor, Hotels Studies Department, Faculty of Tourism \& Hotels, University of Alexandria, Egypt. mostafa.enen@gmail.com

4_-This research derived from Ashery, A. F. A. (2010). Food Preparation and Service Risks in Alexandria Dormitories, Obstacles of HACCP System Implementation Master of Science Thesis, Home Economics Department, Faculty of Agriculture, El-Shatby, University of Alexandria, Alexandria, Egypt.drzizo83@yahoo.com 
average cases of food poisoning outbreaks because people think they have flu or simply do not want to go through the health units ${ }^{(3)}$.

Alexandria University is the second big university in Egypt. The main objective of the accommodation system is to provide an environment conductive to both personal development and academic achievement. Alexandria University offers heavily subsidized housing facilities with capacity of 6058 students from different Egyptian geographical regions. The university dormitories comprise several buildings which are conveniently located near the university Campus. The available facilities include kitchens, dining rooms, laundries, cafeterias, gymnasiums, playgrounds, TV, radio and music rooms, theater and reading rooms. Around 5460 students reside in its four residence branches located in El-Shatby, Saba Basha, Sumouha and Mergham districts depending on statistics published ${ }^{(4)}$.

Contamination was defined as the presence of harmful substances or organisms in food, which transfer from utensils, equipment, or preparing surfaces. Food handling by staff can be a source of crosscontamination as hands are never free of bacteria. Crosscontamination also occurs when food contact surfaces (such as cutting boards) are not kept clean and sanitized ${ }^{(5)}$. Another source of crosscontamination is chemicals, particularly those used for cleaning purposes, such detergents which should be appropriate for the purpose and in no circumstances be allowed to contact the food ${ }^{(6)}$. There was a recommendation that every catering employee must practice good basic hygiene ${ }^{(7)}$.

There are many methods in assaying cleanliness including kitchen surfaces used during food preparation like ATP-bioluminescence which is a rapid assay that depends on detecting adenosine triphosphate (ATP). The ATP bioluminescence as a bio-control method is used as an innovative tool that helps meat processors to reduce safely the use of sanitizer by $35 \%$ and also described as a useful tool for monitoring HACCP and hygiene parameters ${ }^{(8)}$.

A study done compared the results of the method of ATPbioluminescence and the traditional hygiene swabbing method for determination surface cleanliness at a hospital kitchen. The samples collected from worktops, cutting boards and equipment at a hospital kitchen in Turkey. The results revealed that the ATP monitoring method provides rapid results with improved benefits in the control of surface contamination ${ }^{(9)}$, also a study conducted to evaluate ATP bioluminescence swabbing as a monitoring tool for effective hospital cleaning. The study confirmed that this technique was a useful tool for monitoring cleanliness in all hospital departments ${ }^{(10)}$. ATP 
bioluminescence is one of most important method for microbiological measurements in pharmaceutical manufacturing .This technique has gained regulatory acceptance as a tool for releasing certain types of pharmaceutical products ${ }^{(11)}$. In addition, is widely reported as rapid, easy and suitable method for analyzing live microorganisms ${ }^{(12,13)}$.

\section{Objectives of the study:-}

This study aimed to study kitchen hygiene control of Alexandria University dormitories through the following:

1- Using the rapid technique of ATP-bioluminescence to identify the level of cleanness at Alexandria University dormitories.

2- Using a questionnaire to detect the opinion, practice and knowledge of the catering personnel related to the principle of food and personal hygiene.

3- Study the correlation between some dependent variables as age, gender, education, type of work, and years of experience on the score of food safety test as independent variable.

\section{Research Hypotheses:}

1- Kitchen hygiene control of Alexandria University dormitories provide cleanness situation.

2- Practice and knowledge of the catering personnel related to the principle of food and personal hygiene are highly accepted.

3- There is positive correlation between some dependent variables as age, gender, education level, type of work, and years of experience on the score of food safety test as independent variable.

\section{Materials and Methods:}

The study had two parts including: (1) estimating the cleanliness level of the dorms kitchen environment using a quick and simple but effective technique of the ATP-bioluminescence, and (2) determining the opinion and practice of a random sample consisted of 50 catering personnel responsible for food preparing and serving the meals for the students, as well as evaluation their knowledge related to the principles of food safety and hygiene.

\section{1- Estimating the cleanliness level of kitchen environment:}

The kitchen environment safety was determined using the ATP bioluminescence ${ }^{(14)}$. The bioluminescence assay is based upon the light-producing enzyme luciferase that will hydrolyze ATP to produce light. Light production is detected by a luminometer and recorded as relative light units (RLU) ${ }^{(15)}$. 
The samples were collected from fifteen samples (surfaces, equipment, tools, and sinks) at the main kitchen of El-Shatby dormitory branch.

The idea of this technique depends on ATP is found in all cells including animal, plant, bacteria, yeast and mold, and can be used to ascertain the presence or absence of microbial contamination in food samples as well as surfaces of food preparing, tools, and equipment, and storing areas.

The procedure was done according to the following steps:

1- Washing and sanitizing gloves and hands to remove ATP.

2- $\quad$ Sponge surface area with ATP free sponge.

3- Place sponge in a solution that contains trichloroacetic acid as ATP depleting reagent that is capable of isolating and removing the non-microbial ATP that can interfere with the bioluminescence reaction, and sponge the surface again.

4- $\quad$ Swabbing an area of $10 \mathrm{~cm} .10 \mathrm{~cm}\left(100 \mathrm{~cm}^{2}\right)$ with the ATP bio swabs. The swab contains the luciferase as well as D-luciferin. The luciferase enzyme hydrolyses ATP to AMP, releasing the stored energy as visible light, according to the following reaction:

$\mathrm{ATP}+\mathrm{D}$-luciferin $+\mathrm{O}_{2} \longrightarrow \quad$ oxyluciferin $+\mathrm{PPi}+\mathrm{AMP}+\mathrm{CO}_{2}+$ light

5 - $\quad$-Inserting the swab into the chamber of the luminometer to obtain the light measurement. The intensity of the light produced is proportional to the concentration of ATP and thus number of microbial cells.

The following specifies the relationship between relative light units (RLU) versus zones of cleanliness values.

The Zones of Cleanliness range from 0 to 7.9 and are on a logarithmic base -10 scale as used in the Richter scale. A Zone result of 4.0 is ten times greater in light output than 3.0 and a hundred times greater than 2.0.

According to the scale guide line of the ATP bioluminescence assay, the zones which range from 0 to 2.5 is considered "clean", while the caution zones is ranged between 2.6 and 3.0, and readings above 3.0 are considered "dirty". 
Relative Light Units (RLU) versus zones of cleanliness values

\begin{tabular}{|l|l|l|l|l|l|l|l|l|}
\hline & $\mathbf{0}$ & $\mathbf{1}$ & $\mathbf{2}$ & $\mathbf{3}$ & $\mathbf{4}$ & $\mathbf{5}$ & $\mathbf{6}$ & $\mathbf{7}$ \\
\hline $\mathbf{0 . 0}$ & $<=10$ & $\mathbf{1 0 0}$ & $\mathbf{1 , 0 0 0}$ & $\mathbf{1 0 , 0 0 0}$ & $\mathbf{1 0 0 , 0 0 0}$ & $\mathbf{1 , 0 0 0 , 0 0 0}$ & $\mathbf{1 0 , 0 0 0 , 0 0 0}$ & $\mathbf{1 0 0 , 0 0 0 , 0 0 0}$ \\
\hline $\mathbf{0 .}$ I & $\mathbf{1 3}$ & $\mathbf{1 3 0}$ & $\mathbf{1 , 3 0 0}$ & $\mathbf{1 3 , 0 0 0}$ & $\mathbf{1 3 0 , 0 0 0}$ & $\mathbf{1 , 3 0 0 , 0 0 0}$ & $\mathbf{1 3 , 0 0 0 , 0 0 0}$ & $\mathbf{1 3 0 , 0 0 0 , 0 0 0}$ \\
\hline $\mathbf{0 . 2}$ & $\mathbf{I} 6$ & $\mathbf{1 6 0}$ & $\mathbf{1 , 6 0 0}$ & $\mathbf{1 6 , 0 0 0}$ & $\mathbf{1 6 0 . 0 0 0}$ & $\mathbf{1 , 6 0 0 , 0 0 0}$ & $\mathbf{I 6 , 0 0 0 , 0 0 0}$ & $\mathbf{I 6 0 , 0 0 0 , 0 0 0}$ \\
\hline $\mathbf{0 . 3}$ & $\mathbf{2 0}$ & $\mathbf{2 0 0}$ & $\mathbf{2 , 0 0 0}$ & $\mathbf{2 0 , 0 0 0}$ & $\mathbf{2 0 0 , 0 0 0}$ & $\mathbf{2 , 0 0 0 , 0 0 0}$ & $\mathbf{2 0 , 0 0 0 , 0 0 0}$ & $\mathbf{2 0 0 , 0 0 0 , 0 0 0}$ \\
\hline $\mathbf{0 . 4}$ & $\mathbf{2 5}$ & $\mathbf{2 5 0}$ & $\mathbf{2 , 5 0 0}$ & $\mathbf{2 5 , 0 0 0}$ & $\mathbf{2 5 0 , 0 0 0}$ & $\mathbf{2 , 5 0 0 , 0 0 0}$ & $\mathbf{2 5 , 0 0 0 , 0 0 0}$ & $\mathbf{2 5 0 , 0 0 0 , 0 0 0}$ \\
\hline $\mathbf{0 . 5}$ & $\mathbf{3 2}$ & $\mathbf{3 2 0}$ & $\mathbf{3 , 2 0 0}$ & $\mathbf{3 2 , 0 0 0}$ & $\mathbf{3 2 0 , 0 0 0}$ & $\mathbf{3 , 2 0 0 , 0 0 0}$ & $\mathbf{3 2 , 0 0 0 , 0 0 0}$ & $\mathbf{3 2 0 , 0 0 0 , 0 0 0}$ \\
\hline $\mathbf{0 . 6}$ & $\mathbf{4 0}$ & $\mathbf{4 0 0}$ & $\mathbf{4 , 0 0 0}$ & $\mathbf{4 0 , 0 0 0}$ & $\mathbf{4 0 0 , 0 0 0}$ & $\mathbf{4 , 0 0 0 , 0 0 0}$ & $\mathbf{4 0 , 0 0 0 , 0 0 0}$ & $\mathbf{4 0 0 , 0 0 0 , 0 0 0}$ \\
\hline $\mathbf{0 . 7}$ & $\mathbf{5 0}$ & $\mathbf{5 0 0}$ & $\mathbf{5 , 0 0 0}$ & $\mathbf{5 0 , 0 0 0}$ & $\mathbf{5 0 0 . 0 0 0}$ & $\mathbf{5 , 0 0 0 , 0 0 0}$ & $\mathbf{5 0 , 0 0 0 , 0 0 0}$ & $\mathbf{5 0 0 , 0 0 0 , 0 0 0}$ \\
\hline $\mathbf{0 . 8}$ & $\mathbf{6 3}$ & $\mathbf{6 3 0}$ & $\mathbf{6 , 3 0 0}$ & $\mathbf{6 3 , 0 0 0}$ & $\mathbf{6 3 0 , 0 0 0}$ & $\mathbf{6 , 3 0 0 , 0 0 0}$ & $\mathbf{6 3 , 0 0 0 , 0 0 0}$ & $\mathbf{6 3 0 , 0 0 0 , 0 0 0}$ \\
\hline $\mathbf{0 . 9}$ & $\mathbf{7 9}$ & $\mathbf{7 9 0}$ & $\mathbf{7 , 9 0 0}$ & $\mathbf{7 9 , 0 0 0}$ & $\mathbf{7 9 0 , 0 0 0}$ & $\mathbf{7 . 9 0 0 . 0 0 0}$ & $\mathbf{7 9 . 0 0 0 . 0 0 0}$ & $\mathbf{7 9 0 , 0 0 0 , 0 0 0}$ \\
\hline
\end{tabular}

2- Determine the opinion, practice and knowledge of the catering personnel:

A questionnaire was designed to collect data from a random sample of catering personnel (50) who work at Alexandria University dorms. The dependent variables of the studied sample included age, gender, educational level, type of work, and years of experience. Whereas the independent variable was the score of food safety tests as independent variable.

In addition, the questionnaire included a food safety test to identify the knowledge levels of the catering personnel related to hygienic practices to produce and serve safety meals ${ }^{(16)}$.

The questionnaire was given in April 2010 to the dorms administration to be distributed to the catering employees. After three days the complete questionnaires were received from the administration. The data was tabulated and statically analyzed using the descriptive analysis, percentages, frequencies, as well as the correlation between variables using the SPSS version 14.0.

Results and Dissections

\section{1- Cleanliness level of kitchen environment}

Results given in table (1) describe the degree of cleanliness of some surfaces, equipment, tools and sinks according to the scale guide line of the ATP bioluminescence assay. All the examined surfaces including preparation tables, vegetable preparation counter, meat preparation counter, and cutting board were quite dirty because their score values ranged from 4.3 to 5.9. In addition, electric mincer, electric peeler, water glasses, ladles and vegetable washing sinks were also dirty and were scored with values of 4.3, 3.4, 3.5, 3.9, and 3.3, respectively. On the other hands, only four items were described as clean including refrigerator shelves (1.4), knives (1.4), service trays (1.4), and hand washing sink (1.5). Only two items were in the (caution) or (warning) range. They were skewer grilling and cooking 
pans, because their values were 2.7 and 2.6 , respectively. Using the ATP-bioluminescence in the present study indicated that the number of dirty items was highest than the number of clean items, since (9) out of (15) items were described as dirty against only (4) items as clean. Therefore, the percentage of examined dirty items represented (60 \%), whereas the clean items represented only (26.7\%), and caution cases represented $(13.3 \%)$ of the examined samples.

Table (1): Description of some surfaces, equipment, tools and sinks according to its state of cleanliness

\begin{tabular}{|c|c|c|c|}
\hline Examined items & RLU & Score & Specification \\
\hline \multicolumn{4}{|l|}{ Surfaces } \\
\hline - Preparation tables & 7.900 .000 & 5.9 & Dirty \\
\hline - $\quad$ Cutting board & 1.300 .000 & 5.1 & Dirty \\
\hline $\begin{array}{lll}\text { Vegetable } & \text { preparation } \\
\text { counter }\end{array}$ & 790.000 & 4.9 & Dirty \\
\hline - $\quad$ Meat preparation counter & 200.000 & 4.3 & Dirty \\
\hline \multicolumn{4}{|l|}{ Equipment } \\
\hline - Electric mincer & 200.000 & 4.3 & Dirty \\
\hline - $\quad$ Electric peeler & 25.000 & 3.4 & Dirty \\
\hline - $\quad$ Skewer grilling & 5.000 & 2.7 & Caution \\
\hline - $\quad$ Refrigerator shelves & 250 & 1.4 & Clean \\
\hline \multicolumn{4}{|l|}{ Tools } \\
\hline 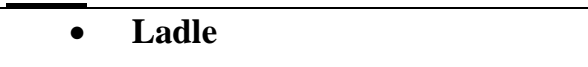 & 79.000 & 3.9 & Dirty \\
\hline - Water glass & 32.000 & 3.5 & Dirty \\
\hline - Cooking pan & 4.000 & 2.6 & Caution \\
\hline - Knife & 250 & 1.4 & Clean \\
\hline - $\quad$ Service tray & 250 & 1.4 & Clean \\
\hline \multicolumn{4}{|l|}{ Sinks } \\
\hline - Vegetable washing sink & 20.000 & 3.3 & Dirty \\
\hline - $\quad$ Hand washing sink & 320 & 1.5 & Clean \\
\hline
\end{tabular}




\begin{tabular}{|l|l|l|}
\hline Demographic & Options & $\mathbf{n}=\mathbf{5 0}$ \\
\cline { 3 - 3 } Characteristics & & $\%$ \\
\hline
\end{tabular}

The interpretation of the dirtiness of most of the examined items may be due to the use of traditional manual and old methods of cleaning and the dependence on the visual inspection only which observed from the second part of this study.

These results reject the first hypothesis kitchen hygiene control of Alexandria University dormitories provide cleanness situation.

\section{2-Demographic Characteristics of Catering Workers:}

Table (2) presents the demographic characteristics of the studied sample of the catering workers. The data in the table (2) indicates that the highest percentage of the catering workers in Alexandria University dormitories was young, as about two third of them (64\%) were less than 40 years old.

Therefore, $(40 \%)$ of the sample had experiences in the field of food preparing and serving ranged from less than 5 years to 10 years. As far as gender, also two third of the studied sample $(66 \%)$ were males, and $(34 \%)$ were females.

Table (2): Percentage distribution of the catering workers according to their demographic characteristics 


\begin{tabular}{|l|l|l|}
\hline \multirow{5}{*}{ Age } & Less than 30 years & 16 \\
\cline { 2 - 3 } & $30-<40$ years & 48 \\
\cline { 2 - 3 } & $40-<50$ years & 28 \\
\cline { 2 - 3 } Gender & $50+$ years & 8 \\
\hline \multirow{4}{*}{ Qualification } & Male & 66 \\
\cline { 2 - 3 } & Female & 34 \\
\hline \multirow{5}{*}{ Years } & Secondary education & 84 \\
\cline { 2 - 3 } & $\begin{array}{l}\text { Upper- intermediate level of } \\
\text { education }\end{array}$ & 16 \\
\hline \multirow{5}{*}{ Experience } & Service provider & 37 \\
\cline { 2 - 3 } & Catering Service provider & 15 \\
\cline { 2 - 3 } & Assistant Chef & 16 \\
\cline { 2 - 3 } & Chef & 32 \\
\cline { 2 - 3 } & Less than 5 & 8 \\
\cline { 2 - 3 } & $>10-16$ & 32 \\
\cline { 2 - 3 } & $>16-22$ & 36 \\
\cline { 2 - 3 } & $>22-28$ & 4 \\
\cline { 2 - 3 } & More than 28 & 4 \\
\hline
\end{tabular}

\section{Kitchen Design:}

According to the data in Table (3), all the studied catering personnel had a positive opinion toward the kitchen design. While (92\%) agreed that the place of garbage disposal is isolated from food preparation and service areas.

From this data it can be concluded that the kitchens of the Alexandria Universities Dormitories are well designed.

\section{Kitchen Facilities:}

As shown from data in Table (3) all the studied catering personnel were satisfied with the kitchen facilities related to cleaning agents and sanitizers, as well as hot water for hand washing. Also, they satisfied with the storage areas for kitchen equipment, utensils and tools, as well as they satisfied with the easily cleaned and disinfected cooking utensils materials.

On the other hand, all of them mentioned that there are no calibrated thermometers for measuring the temperature during cooking foods to avoid under or over cooking and to hold the cooked food out of the danger temperature zone.

\section{Kitchen Organizing Rules:}

As shown from Table (3) $80 \%$ of the studied sample mentioned that the kitchen floor is cleaned according to a timetable. On the other hand, $(56 \%),(80 \%)$, of them had no information about schedule for 
cleaning storage areas as well as the pest control and insects fighting in kitchen and dining halls, respectively.

Regarding to the training programs for personal hygiene, $(84 \%)$ of the sample had a negative opinion toward the rules related to training programs provided for them, and the absence of a written way for cleaning of equipment.

Therefore, this data indicates that there are some limitations in the rules of cleaning storage areas and controlling pests and fighting insects that applied in the kitchens of the Alexandria University Dormitories.

Table (3): Percentage distribution of the catering workers according to their opinion on kitchen design, facilities and organizing rules related to food safety

\begin{tabular}{|l|l|l|l|l|}
\hline & Statement & Yes & No & $\begin{array}{l}\text { Do not } \\
\text { know }\end{array}$ \\
\hline 1 & $\begin{array}{l}\text { Kitchen design: } \\
\text { The kitchen is divided into sections according } \\
\text { to the nature of the food being prepared }\end{array}$ & $\mathbf{1 0 0}$ & $\mathbf{0}$ & $\mathbf{0}$ \\
\hline $\mathbf{2}$ & $\begin{array}{l}\text { The kitchen area is suitable for the size of work } \\
\text { required }\end{array}$ & $\mathbf{1 0 0}$ & $\mathbf{0}$ & $\mathbf{0}$ \\
\hline $\mathbf{3}$ & $\begin{array}{l}\text { There are special places to collect garbage } \\
\text { The place of garbage disposal is isolated from } \\
\text { food preparation and service areas }\end{array}$ & $\mathbf{9 2}$ & $\mathbf{8}$ & $\mathbf{0}$ \\
\hline $\mathbf{1}$ & $\begin{array}{l}\text { Kitchen facilities: } \\
\text { There are sufficient cleaning agent and } \\
\text { sanitizers for hand washing }\end{array}$ & $\mathbf{1 0 0}$ & $\mathbf{0}$ & $\mathbf{0}$ \\
\hline $\mathbf{2}$ & $\begin{array}{l}\text { There is hot water for hand washing } \\
\text { There are places for the storage of equipment } \\
\text { and cutlers in an appropriate manner }\end{array}$ & $\mathbf{1 0 0}$ & $\mathbf{0}$ & $\mathbf{0}$ \\
\hline $\mathbf{3}$ & $\begin{array}{l}\text { Cutlery and cooking utensils are made of } \\
\text { materials easily cleaned and disinfected }\end{array}$ & $\mathbf{1 0 0}$ & $\mathbf{0}$ & $\mathbf{0}$ \\
\hline $\mathbf{5}$ & $\begin{array}{l}\text { There are calibrated thermometers for } \\
\text { measuring the temperature during cooking }\end{array}$ & $\mathbf{0}$ & $\mathbf{1 0 0}$ & $\mathbf{0}$ \\
\hline $\mathbf{1}$ & $\begin{array}{l}\text { Kitchen organizing rules: } \\
\text { Cleaning and maintenance of the kitchen floor } \\
\text { is done according to a specific timetable. }\end{array}$ & $\mathbf{8 0}$ & $\mathbf{1 2}$ & $\mathbf{8}$ \\
\hline
\end{tabular}




\begin{tabular}{|l|l|l|l|l|}
\hline 2 & $\begin{array}{l}\text { There is a regular maintenance and cleaning of } \\
\text { storage areas according to a schedule. }\end{array}$ & $\mathbf{4 4}$ & $\mathbf{0}$ & $\mathbf{5 6}$ \\
\hline 3 & $\begin{array}{l}\text { There are specific programs and for pest } \\
\text { control and insects fighting in the kitchen and } \\
\text { the dining halls. }\end{array}$ & $\mathbf{2 0}$ & $\mathbf{0}$ & $\mathbf{8 0}$ \\
\hline 4 & $\begin{array}{l}\text { There are training programs for personal } \\
\text { hygiene. }\end{array}$ & $\mathbf{1 6}$ & $\mathbf{8 4}$ & $\mathbf{0}$ \\
\hline $\mathbf{5}$ & $\begin{array}{l}\text { There is an approval written way for cleaning of } \\
\text { equipment }\end{array}$ & 16 & 84 & $\mathbf{0}$ \\
\hline
\end{tabular}

These limitations may affect negatively the safety of the meals that provided for the students.

Less percentage (92\%) of the asked workers said that they use tissues when sneezing or coughing and this can be considered as one of the most important personal habit which avoids spread diseases among workers and students. A considerable percentage of the workers (82\%) used to wear gloves during serving food for the students. In a study to develop and test an audit tool for assessing employee food-handling practices in school foodservice examined employee hygiene, and cross-contamination. The most frequently observed problem was the handling of food with bare hands ${ }^{(17) .}$

The results in table (4) also show that workers are suffering from some problems related to hygienic practices such as the insufficient clean clothes to replace the dirty one and the insufficient towels to use them after hand washing. These limitations can be a source of crosscontamination.

Table (4): Percentage distribution of the catering workers according to their practices related to food safety

\begin{tabular}{|l|l|l|l|l|}
\hline & Statement & Yes & No & Do not know \\
\hline 1 & Using tissues when sneezing or coughing & 92 & 8 & 0 \\
\hline 2 & $\begin{array}{l}\text { Wearing gloves during serving food to } \\
\text { students }\end{array}$ & 82 & 18 & 0 \\
\hline 3 & $\begin{array}{l}\text { Using towels after washing hands } \\
\text { immediately }\end{array}$ & 28 & 72 & 0 \\
\hline 4 & $\begin{array}{l}\text { There are extra clean clothes to replace } \\
\text { the dirty ones }\end{array}$ & 26 & 66 & 8 \\
\hline 5 & $\begin{array}{l}\text { Food preparation is done shortly before } \\
\text { serving to keep the holding time as short } \\
\text { as possible }\end{array}$ & 18 & 82 & 0 \\
\hline 6 & $\begin{array}{l}\text { Disinfectant (sanitizers) always used after } \\
\text { used after washing surfaces }\end{array}$ & 8 & 46 & 46 \\
\hline
\end{tabular}

A survey conducted in (2003) surveyed 100 foodservice employees in the United Kingdom about their perceptions of hygiene training and attitudes towards risk management systems. The results indicated that the understanding of risk, hazards, and risk management was low ${ }^{(19) .}$ 
The food safety test include 11 pictures, everyone has a meaning of a related procedure to the principles of food safety and hygiene. The catering personnel were asked to identify each picture. The results in table (5) illustrate the level of catering personnel's knowledge according to their scores of the food safety test.

Table (5) Percentage distribution of the catering workers according to their food safety test score

These results reject the second hypothesis that practice and knowledge of the catering personnel related to the principle of food and personal hygiene are highly accepted

The data of table (6) ) indicates that (26\%) and (22\%) of the studied catering workers had a low score of the food safety test meaning that their knowledge about food safety ranged between weak and fair, respectively and they need to attend training workshops on this subject, and only (8\%) of them got full score of excellent. These results means that the majority of workers need intensive food safety training to ensure offering high quality of food service in the university dorm.

The data in table (6) indicated that a positive significant correlation exist between score of food safety test and the sample education level $\left(\mathrm{r}=0.334^{*}\right)$, years of experience $\left(\mathrm{r}=0.408^{* *}\right)$. On the other hand, there was a negative significant correlation between age $\left(r=-0.313^{*}\right)$, type of work $\left(r=-0.428^{* *}\right)$ and score of food safety test. The value of chi-Square between Age and score of food safety test was $140.79 * *$ indicating that younger workers had the highest grades in answering

\begin{tabular}{|l|l|l|}
\hline $\mathbf{n}=\mathbf{5 0}$ & $\begin{array}{l}\text { Score } \\
(\mathbf{1 0})\end{array}$ & $\mathbf{\%}$ \\
\hline Level of knowledge & $\mathbf{5 . 5}$ & $\mathbf{2 6}$ \\
\hline Weak & $\mathbf{6 . 4}$ & $\mathbf{2 2}$ \\
\hline Fair & $\mathbf{7 . 3}$ & $\mathbf{2 8}$ \\
\hline Good & $\mathbf{8 . 2}$ & $\mathbf{1 6}$ \\
\hline very good & $\mathbf{1 0}$ & $\mathbf{8}$ \\
\hline Excellent &
\end{tabular}

food safety test compared with older workers. The value of ChiSquare between score of food safety test and the sample educational level was $15.09 * *$ indicating that worker with upper- intermediate 
level of education got greater scores than those with secondary education.

The value of Chi-Square between score of food safety test and type of work was $36.37 * *$ indicating that cooks got higher grades scores than their assistants, followed by steward, and food service workers.

Table (6) Correlation between the demographic characteristics of catering workers and score of food safety test

\begin{tabular}{|l|l|l|l|l|l|}
\hline Variable & Age & Gender & $\begin{array}{l}\text { Education } \\
\text { level }\end{array}$ & $\begin{array}{l}\text { Type of } \\
\text { work }\end{array}$ & $\begin{array}{l}\text { Years of } \\
\text { Experience }\end{array}$ \\
\hline $\begin{array}{l}\text { score of } \\
\text { food safety } \\
\text { test }\end{array}$ & $\mathbf{- 0 . 3 1 3 ^ { * }}$ & $\mathbf{- 0 . 2 0 7}$ & $\mathbf{0 . 3 3 4} *$ & $-\mathbf{0 . 4 2 8}^{* *}$ & $\mathbf{0 . 4 0 8 * *}$ \\
\hline
\end{tabular}

**Correlation is significant at the 0.01 level

*Correlation is significant at the 0.05 level

The value of Chi-Square between score of food safety test and years of experience was $101.39 * *$ indicating that workers with experience (less than 5 years) got more correct answers than those with more years of experience. These results indicate that the younger catering worker may be more interested to be aware with the updated information related to food safety.

The results indicate also the importance of offering training program to all the employees and use precise measurements to assure attaining the results of these trainings.

These results reject the third hypothesis which shows positive correlation between some dependent variables as education level and years of experience and negative correlation between age, gender, and type of work, on the score of food safety test as independent variable. 


\section{References:}

1- Eves, A., and Dervisi, P. (2005). Experiences of the Implementation and Operation of HACCP in the Foodservice Sector. International Journal of Hospitality Management, Issue (24), pp. 3 -19.

2- FDA (U.S Food and Drug Administration). (2004). FDA Report on The Occurrence of Food-borne Illness Risk Factors in Selected Institutional Foodservice, Restaurant, and Retail Food Store Facility Types. [Electronic version]. College Park, MD: Center for Food Safety and Applied Nutrition. http://www.cfsan.fda.gov/ dms/retrsk2.html.

3- Agriculture Research Center (ARC). (2003). Egyptian Food Safety Project: Design or a Master Plan of Food Safety for the Private Sector. Ministry of Agriculture and Land Reclamation. Cairo University St., Giza, Egypt.

4- University of Alexandria internet site: http://www.alex.edu.eg/?q=StudentAccommodation uploaded on $30 / 01 / 2011$

5- Loken, J., Hony, K., Safe, K. (1995). The HACCP Food Safety Manual, New York: John Wiley \& Sons, Inc. 38-94.

6- Knowles, T. (2002). Food Safety In The Hospitality Industry. Butterworth-Heinemann, Oxford, UK. 
7- Arduser, L., and Brown, R. D. (2005). HACCP and Sanitation in Restaurants and Food Service Operations $\left(1^{\text {st }}\right.$ Ed). Atlantic Publishing Group, Inc, USA, 12-42, 126-157, 256-315.

8- Pallett, A. (2006). Innovative Tool Helps Meat Processor Safely Reduce Sanitizer. Food Sci. Technol. Today 11, 15-24.

9- Aycicek ,H., Oguz ,U., and Koray,K.(2006).Comparison of Results of ATP Bioluminescence and Traditional Hygiene Swabbing Methods for The Determination of Surface Cleanliness at A Hospital Kitchen . Int. J. Hyg. Environ-Health 209(2006) 203-206.

10-Willis, C., and Moriey, R. (2007). Evaluate of ATP Bioluminescence Swabbing as A Monitoring and Training Tool for Effective Hospital Cleaning. British Journal of Infection Control, Vol.8, No. 5, 17-21.

11-Greenwood, M., and Westbury, J. (2007). Using ATP Bioluminescence For Microbiological Measurements in Pharmaceutical Manufacturing. [On Line].Available at: www. Science Direct.com

12-Cho, M., and Yoon, J. (2007). The Application of Bioluminescence Assay with Culturing for Evaluating Quantitative Disinfection Performance .Water Research 41(2007) 741-746. [On Line].Available at: www. Science Direct.com.

13-Streifel, A., Hendrickson, C., Mark, G., and Guelcher, A. (2009). ATP Bioluminescence Testing of Hospital Surfaces as A Means to Evaluate Hospital Environment Cleanliness and Identify Performance Opportunities in Environmental Management. American journal of Infection Control, (89), PP. 211-234.

14- Bio-control Company. (2010). Using The ATP Bioluminescence. 25 A Nagieb Mahfouz St. New Merko Building. Deglla -Maady, Cairo.

15- Hansen, D., Hilgenhoner, M., and Popp, w. (2008). ATP Bioluminescence-for kitchen Hygiene and Cleaning Control of Surgical Instruments. International J. of Infection Control, 1-4.

16- Paster, T. (2007). The HACCP Food Safety Training Manual, New Gersy: Canada, 75-142.

17- Giampaoli, J., Cluskey, M., and Sneed, J. (2002b). Developing A Practical Audit Tool for Assessing Employee Food-Handling Practices. The Journal of Child Nutrition and Management 26 (1). Available at http://www.asfsa. /childnutrition/ jcnm/02spring /giampaoli2/. Accessed April 23, 2004. 
18- Youn, S., and Sneed, J. (2003). Implementation of HACCP and Prerequisite Programs in School Foodservice. Journal of the American Dietetic Association, 103 (1), 55-60.

19- Worsfold, D., and Griffith, C.J. (2003). Widening HACCP Implementation in the Catering Industry. Food Service Technology, 3 (4), 113-126.
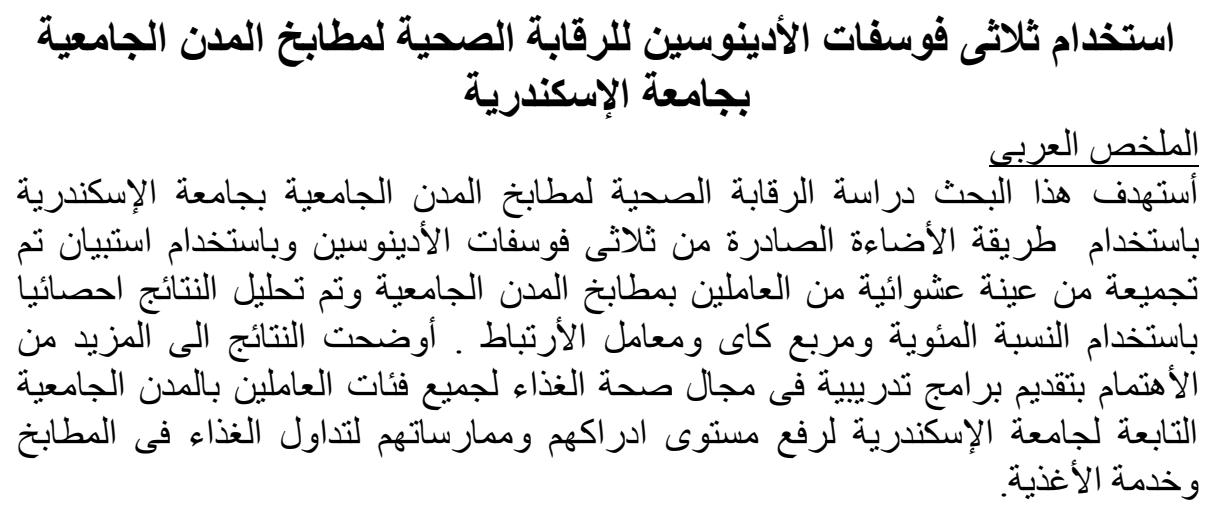

\section{Summary:}

Estimating the cleanliness level of kitchen environment:

All the examined surfaces including preparation tables, vegetable preparation counter, meat preparation counter, and cutting board were quite dirty because score values ranged from 4-3 to 5.9 .In addition, electric mincer, electric peeler, water glasses, ladles and vegetable washing sinks were also dirty and score with values of $4.3,3.4,3.5$, 3.9 , and 3.3, respectively. On the other hands, only four items were described as clean including refrigerator (1.4), knives (1.4), service 
trays (1.4), and hand washing sink (1.5). Only two items were in the (caution) or (warning) range, skewer grilling and cooking utensils, their values were 2.7 and 2.6, respectively. So, the first hypothesis rejected.

Determine the opinion, practice and knowledge of the catering personnel:

The highest grades in answering food safety test got by younger workers compared with older workers, worker with upperintermediate level of education compared with secondary education, cooks compared with assistants, followed by steward, and food service workers with experience (less than 5 years) compared with more years of experience. So, the second hypothesis rejected.

These results reject the third hypothesis which shows positive correlation between some dependent variables as education level and years of experience and negative correlation between age, gender, and type of work, on the score of food safety test as independent variable. 